\title{
Fingolimod Immune Effects Beyond Its Sequestration Ability
}

Francesco Sica $\cdot$ Diego Centonze $\cdot$ Fabio Buttari

Received: August 2, 2019 / Published online: November 6, 2019

(C) The Author(s) 2019

\section{ABSTRACT}

Fingolimod is the first orally administered drug approved for the treatment of relapsing-remitting multiple sclerosis (MS). This drug, modulating sphingosine receptors, regulates the trafficking of lymphocytes between primary and secondary lymphoid organs, trapping naïve $\mathrm{T}$ cells and central memory $\mathrm{T}$ cells in secondary lymphoid organs, without affecting effector memory $\mathrm{T}$ cells and therefore without compromising immunosurveillance. Additionally, fingolimod inhibits expression of Th1 and Th17 cytokines and enhances regulatory T-cell differentiation. It also acts on the $\mathrm{B}$ arm of immunity through an increased ratio of naïve to memory B cells, higher percentage of plasma cells, and highly increased proportion of transitional B cells as well as additional regulatory subsets. Fingolimod treatment enhances the capacity of regulatory B cells to transmigrate across brain endothelial cells. In fact, patients

Enhanced Digital Features To view enhanced digital features for this article go to https://doi.org/10.6084/ m9.figshare.10012466.

F. Sica $\cdot$ D. Centonze $\cdot$ F. Buttari

Unit of Neurology, IRCCS Neuromed, Pozzilli, IS, Italy

D. Centonze ( $\square)$

Department of Systems Medicine, Tor Vergata

University, Rome, Italy

e-mail: centonze@uniroma2.it treated with fingolimod have increased regulatory B-cell frequency in the cerebrospinal fluid. These findings suggest a novel role for fingolimod in MS, by both direct effects and indirect partitioning effects on lymphocytes.

Keywords: B lymphocytes; Fingolimod; T lymphocytes; Mechanism of action

\section{Key Summary Points}

This paper shows new effects of fingolimod on the immune system beyond its sequestration ability.

Fingolimod is an effective drug in adults with relapsing-remitting MS and in pediatric forms of the disease.

Fingolimod negatively regulates $\mathrm{Th} 1$ and Th17 differentiation while promoting Th2 differentiation.

Fingolimod exerts its effects through action on B lymphocytes.

Fingolimod not only modulates lymphocyte trafficking but is able to modulate the composition of B- and T-cell subsets. 


\section{INTRODUCTION}

Fingolimod is the first orally administered drug approved for the treatment of relapsing-remitting multiple sclerosis (MS). Fingolimod derives from myriocin, a metabolite of the fungus Isaria sinclairii [35]. Unlike myriocin, fingolimod does not affect the palmitoyltransferase and does not inhibit the activation and proliferation of $\mathrm{T}$ and B cells [11]. It is structurally similar to endogenous sphingosine and takes part in physiological sphingolipid signaling [31]. Because of its structural similarity to sphingosine, it is phosphorylated to fingolimod phosphate by two protein kinases, type- 1 and type- 2 sphingosine kinase (SphK1 and -2), enabling it to interact with sphingosine receptors.

Sphingosine-1-phosphate (S1P) is a lipid that interacts with $G$ protein-coupled receptors expressed by various cell types in both the central nervous system (CNS) and the periphery. These receptors perform a variety of biological functions, including CNS homeostasis, vascular development, and circulation of T cells [41]. There are five types of sphingosine receptors, namely S1P1, S1P2, S1P3, S1P4, and S1P5. Fingolimod interacts with all these receptors except S1P2 [31]. It plays the role of superagonist of S1P1Rs, implying its overactivation and subsequent internalization, therefore working as a functional antagonist [2].

To date, the cause of MS is still unknown, but the activation of potentially autoreactive myelin-specific $\mathrm{CD}^{+}{ }^{+} \mathrm{T}$ lymphocytes is considered the initial event in its pathogenesis. Activated autoreactive $\mathrm{T}$ lymphocytes express on their surface adhesive molecules that allow them to bind to the endothelial cells of the blood-brain barrier (BBB). These cells produce matrix metalloproteinase enzymes that disrupt the BBB, allowing activated $\mathrm{T}$ lymphocytes to reach the cerebral parenchyma. Following entry into the CNS, $T$ cells accumulate within perivascular spaces, where they encounter myelin antigens presented by the major histocompatibility complex class II (MHC II) molecules expressed by the antigen-presenting cells [23]. This results in reactivation of autoreactive $\mathrm{T}$ cells, secretion of proinflammatory cytokines, and activation of local microglia, leading to progressive damage to cerebral tissue [22].

The resulting CNS damage is a trio of inflammation, demyelination, and neurodegeneration [36]. This article is based on previously conducted studies and does not contain any studies with human participants or animals performed by any of the authors.

\section{Effects of Fingolimod on T Cells}

Physiologically, after antigenic stimulation, lymphocytes can differentiate into two types of memory $\mathrm{T}$ lymphocytes in the lymph nodes: central memory $\mathrm{T}$ cells (TCMs) and effector memory T cells (TEMs) [6].

The type of T-cell differentiation depends on the intensity of antigenic stimulation of naïve $\mathrm{T}$ cells in the lymph nodes. High-intensity antigenic stimulation of naïve $T$ cells generates $C-C$ chemokine receptor 7 (CCR7) ${ }^{-}$effector memory $\mathrm{T}$ cells, which recirculate to infected tissues and display effector functions. Weaker-intensity stimulation generates $\mathrm{CCR}^{+}{ }^{+}$central memory $\mathrm{T}$ cells, which are retained in secondary lymphoid organs. CCR7 is a chemokine involved in T-cell retention in the lymph node

TEMs, once out of the lymph node, reach the peripheral circulation and perform an immunosurveillance function. TCMs, on the other hand, require further antigenic stimulation to differentiate into TEMs in a specific tissue. Most of the pathogenetic TEMs in MS are derived from TCMs that interact once again with myelin antigens in the CNS. This interaction leads to damage to the nerve structures [12].

TCMs recirculate between the blood and secondary lymphoid organs in a CCR7-dependent manner.

They require activation of the S1P1 receptor to egress from lymph nodes, overriding CCR7mediated retention in lymph nodes. TEM cells irreversibly lose CCR7, becoming independent of sphingosine signaling for egress from lymph nodes. The balance between CCR7 retention signals and S1P1 egress signals determines the T-cell egress from lymph node to the blood [21]. 
Fingolimod, after phosphorylation, binds to S1P1 receptors on T cells and causes internalization of the receptor. This reduces the responsiveness of T cells to the egress signal S1P and favors CCR7-mediated retention in lymph nodes [48].

Fingolimod blocks only the central memory $\mathrm{T}$ cells in the lymph nodes, without compromising the circulation of effector memory $\mathrm{T}$ cells. This mechanism limits the formation of new self-reactive lymphocyte clones supporting the disease, without compromising the defense against pathogens [3].

In humans, a preferential retention of $\mathrm{CD} 4^{+}$ compared with $\mathrm{CD}^{+} \mathrm{T}$ cells occurs, and this is related to the higher content of $\mathrm{CCR}^{+}$naive cells in the $\mathrm{CD}^{+}{ }^{+}$compartment [56].

Central memory lymphocyte subsets are believed to be important for inducing the neurological damage associated with multiple sclerosis; their containment in lymphoid tissues is therefore expected to have beneficial effects in MS patients. As a result of cell retention within lymphoid tissues, peripheral blood lymphocyte counts are reduced during treatment with fingolimod. This effect is readily reversed when treatment is stopped, because lymphocytes are redistributed and not destroyed. Intrinsic lymphocyte functions are not affected by treatment with fingolimod [14]. Moreover, much evidence indicates that fingolimod may also exert direct effects within the CNS. Following oral administration, it is found in the CNS where S1P receptors are expressed on most neural lineages and resident cells, particularly glia and neurons. By modulating the S1P receptors expressed on CNS cells [9, 29], fingolimod may have a direct impact on neuropathological processes such as neurodegeneration, gliosis, and endogenous repair mechanisms [7].

The efficacy of fingolimod in MS patients has been confirmed in phase 3 clinical trials. In placebo-controlled trials, fingolimod reduced the relapse rate by approximately 50\%, MRI activity by over $70 \%$, and brain volume loss by 34\%. Confirmed Expanded Disability Status Scale (EDSS) progression was significantly reduced in only one study [33].

The efficacy of fingolimod in pediatric MS was also recently demonstrated, proving more effective than interferon $\beta-1 \mathrm{a}$ in controlling disease activity measured by relapse rate and MRI parameters. Moreover, pediatric MS patients treated with fingolimod experienced less disability progression for up to 2 years [17].

It is a matter of fact that fingolimod works by modulating lymphocyte trafficking. However, in recent years, scientific evidence has shown other mechanisms of action potentially involved in the immunomodulatory effects of this drug. Th1 and Th17 cells play important roles in MS development [39], and accordingly, both cell types are increased in frequency in the circulating blood in MS patients [13]. These cells produce proinflammatory cytokines such as IL1 $\beta$ and IL17, and contribute to disease development and activity [47]. Ex vivo studies showed that fingolimod affects the phenotype and function of circulating T cells. DominguezVillar et al. examined the in vivo effects of fingolimod on $\mathrm{T}$ cells and regulatory $\mathrm{T}$ cells (Treg) among relapsing-remitting MS patients during a 12-month treatment period. Consistent with previous observations, these authors found a clear reduction in the number of total lymphocytes, $\mathrm{CD}^{+} \mathrm{T}$ cells, $\mathrm{CD} 4^{+} \mathrm{T}$ cells, $\mathrm{CD}^{+} \mathrm{T}$ cells, and $\mathrm{B}$ cells after the third month of treatment, with no effects on monocyte and natural killer (NK) cell counts. The level of circulating proinflammatory cytokines was also reduced. TNF and IL27, Th1-related cytokines, were significantly decreased after 3 months of fingolimod therapy. Effector CD4 T cells significantly downregulated the transcription factors RORC and TBX21 (main regulators of Th1 and Th17 cells) and significantly upregulated the exhaustion marker Tim-3. Consequently, ex vivo stimulation of effector $\mathrm{T}$ cells exposed to fingolimod showed reduced production of IL17 and increased IL10. It remains to be clarified whether the effect observed in T cells is due to direct signaling of fingolimod, or whether the change in $\mathrm{T}$ helper phenotypes is due to an indirect effect through antigen-presenting cell modulation [18].

A recently discovered mechanism of action of fingolimod is the modulation of T-cell factor 1 (TCF-1) in CD4 cells. TCF-1 is a transcription factor involved in T-cell development; it negatively regulates Th1 and Th17 differentiation while 
promoting Th2 differentiation via stimulation of Th2-specific transcription factor (GATA3). In mice, TCF-1 expression was found to be involved in the regulation of inflammatory Th1 and Th17 differentiation and the development of experimental autoimmune encephalomyelitis (EAE), the most commonly used animal model for MS. Mazzola and colleagues observed that fingolimod treatment was able to restore the reduced TCF-1 expression in $\mathrm{T}$ cells from relapsing-remitting patients, inducing a less inflammatory phenotype with reduced production of IFN $\gamma$ and granzyme $\mathrm{B}$ [43]. A similar effect has been found in the $\mathrm{CD}^{+}$ compartment. The levels of circulating $\mathrm{CD}^{+} \mathrm{T}$ cells producing IFN $\gamma$ and IL17 appear to be decreased after only a month of fingolimod therapy [54].

The fingolimod mechanism of action negatively affects the migration of new $\mathrm{T}$ cells from the thymus, resulting in a reduction in naïve $T$ cells and an increase in memory phenotypes. This effect might potentiate the shift toward an older immune system, detected in MS patients, and at the same time may reduce regulatory T-cell function. Haas et al. showed that while the number of naïve and recent thymic emigrants in the peripheral T cells of MS patients was reduced, exposure to fingolimod did not deteriorate this imbalance. The number of Treg expressing two TCR-V $\alpha$ chains and the prevalence of conventional $\mathrm{CD}^{+} \mathrm{T}$ cells expressing two TCR-V $\alpha$ chains, both surrogate markers of thymic T-cell development, did not change after 3 and 6 months of fingolimod therapy. Taken together, these observations seem to exclude an effect of fingolimod on the release of $\mathrm{T}$ cells from the thymus [26].

The ability of fingolimod to polarize $\mathrm{T}$ cells toward an anti-inflammatory phenotype is probably related to its effects on antigen-presenting cells such as dendritic cells (DCs). $\mathrm{CD}_{1 \mathrm{c}^{+}}$dendritic cells from fingolimod-treated patients produce lower levels of proinflammatory cytokines, such as IL1 $\beta$ and IL6, after lipopolysaccharide (LPS) stimulation. Such a different pattern of cytokine production by dendritic cells affects their ability to stimulate T cells. Pretreatment of DCs with fingolimod leads to reduced proliferation and significantly less production of TNF $\alpha$ and IFN $\gamma$ by T cells [40].
Fingolimod also affects innate immunity by influencing monocyte function. Supernatants of cultivated monocytes from fingolimod-treated patients show altered secretion of IL1 $\beta$ and TNF $\alpha$ after LPS stimulation. This result confirms a reduced proinflammatory response by monocytes during treatment with fingolimod [40].

In addition to an increase in myelin-reactive cells, MS is characterized by a deficit of peripheral tolerance due to a reduction in regulatory $\mathrm{T}$ cells [25]. Fingolimod in vivo was found to significantly increase the proportion of Treg cells $\mathrm{CD} 4{ }^{+} \mathrm{CD} 25^{\text {high }} \mathrm{CD} 127^{\text {low }}$ from the third month of therapy. This increase leads to a normalization of Treg cells comparable to those in healthy subjects.

All these results support the idea that fingolimod controls MS not only by reducing proinflammatory cell levels but also by increasing immune tolerance $[18,54]$.

\section{Effects of Fingolimod on B Cells}

MS has traditionally been considered to be mediated by CNS reactive $\mathrm{CD} 4^{+} \mathrm{T}$ cells. However, the finding of B-cell depletion by antiCD20 antibodies in MS, leading to a substantial reduction in the development of new brain lesions and relapses [4, 32], indicates an important role for B cells as mediators of MS disease activity. This role may include the production of autoreactive antibodies, abnormal antigen-presenting capacity, altered cytokine response, and possibly impaired number or function of regulatory B cells (Breg), all leading to increased activation of autoreactive CD4 T cells $[5,38,42]$. B cells in the CNS may also enhance the generation of ectopic lymphoid follicles, which have recently been described in the meninges of patients with progressive MS and are considered to be related to cortical neuronal damage $[28,53]$. It was shown that memory B cells, which are increased in MS patients, produce proinflammatory cytokines [19] and can efficiently present myelin antigens to $T$ cells [27]. By contrast, transitional B cells possess anti-inflammatory properties in humans [8] and mice [20]. The percentage of regulatory B cells is significantly increased in MS patients 
treated with fingolimod; thus the increased proportion of transitional cells during treatment may suggest $B$ cells remaining in the periphery [24]. The differential reduction of immune cells in the periphery has been attributed to the cellular level of CCR7 [30, 45].

In addition, $B$ cells in the cerebrospinal fluid of MS patients are reported to exclusively express the memory B cell phenotype [15], suggesting that these cells are preferentially recruited to the CNS of patients with MS. The observed reduction in memory B cells in MS patients treated with fingolimod is thought to be due to the suppression of memory B cells migrating to the CNS [46].

It is interesting to note that an increased proportion of transitional B cells has been demonstrated in association with the beneficial effects of B-cell depletion by anti-CD20 antibody in lupus $[1,51]$ and by alemtuzumab in MS [34], suggesting that transitional B cells are associated with the benefit of treatments that remove B cells from the circulation.

Only recently, the capacity of B cells to control T-cell responses was demonstrated-for instance the ability of regulatory $\mathrm{B}$ cells to suppress Th1 and Th17 differentiation while favoring the generation of Treg [24]. Thus, the observed reduction in the proportion of circulating B cells with suppressed proinflammatory (TNF) and enhanced anti-inflammatory (IL-10) cytokine profiles among the remaining B cells in patients receiving fingolimod should contribute to suppressing proinflammatory B cells entering the CNS, leading to a reduction in disease activity [10].

IL10 downregulates the immune response by reducing production of proinflammatory cytokines, expression of co-stimulatory molecules, and antigen presentation [49]. The increase in $\mathrm{IL}^{+} 0^{+}$cells is most likely due to the higher proportion of IL10-producing transitional cells and of plasmablasts and plasma cells, the main B-cell producers of both IL10 and IL35 regulatory cytokines [16].

Circulating B cells after 3 months of fingolimod therapy were found to produce increased levels of both anti-inflammatory and proinflammatory cytokines, despite the relative reduction in memory cells [10], which in general produce more cytokines than naïve cells $[16,19]$. This may be due to the unchanged and elevated proportions of plasmablasts and plasma cells, respectively, and indicates that the remaining $B$ cells are in a more activated state Breg are thought to suppress the pathogenic $\mathrm{T}$ cells through the production of IL10, IL35, and TGF $\beta[50,52]$. The ratios of TGF $\beta$ to either LT $\alpha$ or TNF and the ratio of IL4 to LT $\alpha$ were elevated after 3 months therapy with fingolimod, suggesting that the overall cytokine profile becomes more anti-inflammatory. TGF $\beta$ can trigger a vast array of regulatory responses including inhibition of antigen presentation and induction of Treg [37, 50]. However stimulation of TGF $\beta$ together with pro-inflammatory IL6 has been shown in myelin-reactive T cells to abrogate their pathogenic function and increase IL10 production, despite also increasing IL17 [44]. Moreover, the reduced expression level of CD80 in fingolimod-treated patients suggests that their B cells have suppressed antigen-presenting capacity. The drug also reduces the percentage of ICAM-1 cells, confirming that fingolimod may reduce antigenpresenting capacity [55].

Considering the effects of fingolimod treatment on lymphocyte migration in the periphery, Grutzke and colleagues asked whether it also influences lymphocyte transmigration across the blood-brain barrier. They therefore investigated the migratory properties of peripheral blood mononuclear cell compartment in an in vitro model of the BBB. Fingolimod treatment demonstrated no affect on the migration of $\mathrm{T}$ cells under either non-inflamed or inflamed conditions. In contrast to $\mathrm{T}$ cells, B cells derived from fingolimod display significantly enhanced migratory activity, which could be attributed to a selective increase in the migration of regulatory B cells. This difference was more pronounced during transmigration across a non-inflamed endothelial cell layer but could be observed under inflamed conditions as well. While there was no difference in the transmigratory capacity of naïve and memory B cells between the groups, a profound increase in transmigration of regulatory B cells derived from fingolimod-treated patients was observed compared with healthy 
controls and untreated MS patients. Moreover, after $\geq 12$ months of treatment, the group of "stable" patients exhibited a significantly higher percentage of regulatory B cells in the peripheral blood than the group of "active" patients, whereas before initiation of treatment there was no difference in this respect between the groups. Although fingolimod significantly reduces the absolute numbers of B-cell subpopulations in the periphery, the CSF in patients receiving fingolimod exhibits naïve and memory B-cell counts comparable to those of control individuals, and even increased numbers of regulatory B cells. These findings support the perception that fingolimod treatment enhances the migration of B cells across the BBB [24].

\section{DISCUSSION}

Fingolimod, interacting with sphingosine receptors, leads to quantitative and qualitative changes in a wide range of immune cells. This drug, after phosphorylation, binds to S1P1 receptors on $\mathrm{T}$ cells and causes internalization of the receptor, reducing the responsiveness of $T$ cells to the egress sphingosine signal and favoring CCR7-mediated retention in lymph nodes.

To date, the block of the central memory $\mathrm{T}$ cells in the lymph node, without compromising the circulation of effector memory T cells, is the best known fingolimod mechanism of action. This mechanism limits the formation of new self-reactive lymphocyte clones supporting the disease, without compromising the defense against pathogens.

However, recent evidence shows that the drug performs different actions on $\mathrm{T}$ and $\mathrm{B}$ lymphocytes.

Fingolimod therapy significantly reduces Th1-related cytokines, such as TNF $\alpha$ and IL27, on $\mathrm{CD}^{+} \mathrm{T}$ cells in vivo, while at the same time increasing the expression of exhaustion markers. A similar effect has been found in the $\mathrm{CD}^{+}$ compartment, with decreased levels of circulating $\mathrm{CD}^{+} \mathrm{T}$ cells producing IFN $\gamma$ and IL17 appearing already after only a month of fingolimod therapy.

The ability of fingolimod to induce a shift in $\mathrm{T}$ cells toward an anti-inflammatory phenotype is probably related to its effect on dendritic cells. CD1c ${ }^{+}$dendritic cells from fingolimodtreated patients produce lower levels of proinflammatory cytokines after lipopolysaccharide stimulation.

Recent evidence confirms that fingolimod affects B cells as well. The percentage of regulatory and transitional B cells in treated MS patients is significantly increased, thus inducing an anti-inflammatory shift. Fingolimod may also reduce the antigen-presenting capacity of $\mathrm{B}$ cells; the reduced expression of CD80 and ICAM-1 cells seems to confirm this possibility.

\section{CONCLUSION}

In summary, fingolimod is found to play a novel and as yet unrecognized role, modulating the composition of B- and T-cell subsets by increasing the ratio of naïve cells to memory cells and significantly increasing the proportion of transitional cells and several other regulatory subsets, including IL $10^{+}$cells.

\section{ACKNOWLEDGEMENTS}

Funding. No funding or sponsorship was received for this study or publication of this article. The Rapid Service Fee was funded by the authors.

Authorship. All named authors meet the International Committee of Medical Journal Editors (ICMJE) criteria for authorship for this article.

Disclosures. Francesco Sica has served on advisory boards for Merck Serono and has received travel grants from Merck Serono, Teva, Biogen, Sanofi-Genzyme, and Novartis. Diego Centonze is an advisory board member of Almirall, Bayer Schering, Biogen, GW Pharmaceuticals, Merck Serono, Novartis, Roche, Sanofi-Genzyme, and Teva, and has received honoraria for speaking or consultation fees from Almirall, Bayer Schering, Biogen, GW Pharmaceuticals, Merck Serono, Novartis, 
Roche, Sanofi-Genzyme, and Teva. He is also the principal investigator in clinical trials for Bayer Schering, Biogen, Merck Serono, Mitsubishi, Novartis, Roche, Sanofi-Genzyme, and Teva. His preclinical and clinical research was supported by grants from Bayer Schering, Biogen Idec, Celgene, Merck Serono, Novartis, Roche, Sanofi-Genzyme, and Teva. Fabio Buttari has served on advisory boards for Teva, Biogen, Merck Serono, and Roche, and has received travel grants and/or speaker honoraria from Merck Serono, Teva, Biogen, Sanofi-Genzyme, and Novartis.

Compliance with Ethics Guidelines. This article is based on previously conducted studies and does not contain any studies with human participants or animals performed by any of the authors.

Open Access. This article is distributed under the terms of the Creative Commons Attribution-NonCommercial 4.0 International License (http://creativecommons.org/licenses/ by-nc/4.0/), which permits any noncommercial use, distribution, and reproduction in any medium, provided you give appropriate credit to the original author(s) and the source, provide a link to the Creative Commons license, and indicate if changes were made.

\section{REFERENCES}

1. Anolik JH, Barnard J, Owen T, Zheng B, Kemshetti S, Looney RJ, et al. Delayed memory B cell recovery in peripheral blood and lymphoid tissue in systemic lupus erythematosus after B cell depletion therapy. Arthritis Rheum. 2007;56:3044-56.

2. Arnon TI, Xu Y, Lo C, Pham T, An J, Coughlin S, Dorn GW, Cyster JG. GRK2-dependent S1PR1 desensitization is required for lymphocytes to overcome their attraction to blood. Science. 2011;333(6051):1898-903.

3. Balandina A, Lecart S, Dartevelle P, Saoudi A, Berrih-Aknin S. Functional defect of regulatory CD4(+)CD25+ T cells in the thymus of patients with autoimmune myasthenia gravis. Blood. 2005;105:735-41.
4. Bar-Or A, Calabresi PA, Arnold D, Markowitz C, Shafer S, Kasper LH, et al. Rituximab in relapsingremitting multiple sclerosis: a 72-week, open-label, phase I trial. Ann Neurol. 2008;63:395-400.

5. Bar-Or A, Fawaz L, Fan B, Darlington PJ, Rieger A, Ghorayeb $\mathrm{C}$, et al. Abnormal B-cell cytokine responses a trigger of T-cell-mediated disease in MS? Ann Neurol. 2010;67:452-61.

6. Baecher-Allan C, Wolf E, Hafler DA. Functional analysis of highly defined, FACS-isolated populations of human regulatory CD4 + CD25 + T cells. Clin Immunol. 2005;115:10-8.

7. Baumruker T, Billich A, Brinkmann V. FTY720, an immunomodulatory sphingolipid mimetic: translation of a novel mechanism into clinical benefit in multiple sclerosis. Expert Opin Investig Drugs. 2007;16(3):283-9.

8. Blair PA, Noreña LY, Flores-Borja F, Rawlings DJ, Isenberg DA, Ehrenstein MR, et al. $\mathrm{CD} 19^{+} \mathrm{CD} 24^{\mathrm{hi}} \mathrm{CD} 38^{\mathrm{hi}} \mathrm{B}$ cells exhibit regulatory capacity in healthy individuals but are functionally impaired in systemic lupus erythematosus patients. Immunity. 2010;32:129-40.

9. Birgbauer E, Chun J. New developments in the biological functions of lysophospholipids. Cell Mol Life Sci. 2006;63(23):2695-701.

10. Blumenfeld S, Staun-Ram E, Miller A, et al. Fingolimod therapy modulates circulating B cell composition, increases B regulatory subsets and production of IL-10 and TGF $\beta$ in patients with multiple sclerosis. J Autoimmun. 2016;70: 40-51.

11. Brinkmann V, Chen S, Feng L, Pinschewer D, Nikolova Z, Hof R. FTY720 alters lymphocyte homing and protects allografts without inducing general immunosuppression. Transpl Proc. 2001;33:530-1.

12. Brinkmann $\mathrm{V}$, Billich $\mathrm{A}$, Baumruker $\mathrm{T}$, Heining $\mathrm{P}$, Schmouder R, Francis G, Aradhye S, Burtin P. Fingolimod (FTY720): discovery and development of an oral drug to treat multiple sclerosis. Nat Rev Drug Discov. 2010;9(11):883-97.

13. Cao Y, Goods BA, Raddassi K, Nepom GT, Kwok WW, Love JC, et al. Functional inflammatory profiles distinguish myelin-reactive $\mathrm{T}$ cells from patients with multiple sclerosis. Sci Transl Med. 2015;7:287ra74.

14. Chun J, Hartung HP. Mechanism of action of oral fingolimod (FTY720) in multiple sclerosis. Clin Neuropharmacol. 2010;33(2):91-101. 
15. Corcione A, Casazza S, Ferretti E, Giunti D, Zappia E, Pistorio A, et al. Recapitulation of B cell differentiation in the central nervous system of patients with multiple sclerosis. Proc Natl Acad Sci USA. 2004;101:11064-9.

16. Dang VD, Hilgenberg E, Ries S, Shen P, Fillatreau S. From the regulatory functions of $B$ cells to the identification of cytokine-producing plasma cell subsets. Curr Opin Immunol. 2014;28:77-83.

17. Deiva K, Huppke P, Banwell B, Chitnis T, Gärtner J, Krupp L, Waubant E, Stites T, Pearce GL, Merschhemke M. Consistent control of disease activity with fingolimod versus IFN $\beta$-1a in paediatric-onset multiple sclerosis: further insights from PARADIGMS. J Neurol Neurosurg Psychiatry. 2019;1-9.

18. Dominguez-Villara M, Raddassia K, Danielsena AC, Guarnaccia J, Hafler DA. Fingolimod modulates T cell phenotype and regulatory $\mathrm{T}$ cell plasticity in vivo. J Autoimmun. 2019;96:40-9.

19. Duddy M, Niino M, Adatia F, Hebert S, Freedman M, Atkins H, Kim HJ, Bar-Or A. Distinct effector cytokine profiles of memory and naive human B cell subsets and implication in multiple sclerosis. Immunol. 2007;178(10):6092-9.

20. Evans JG, Chavez-Rueda KA, Eddaoudi A, MeyerBahlburg A, Rawlings DJ, Ehrenstein MR, et al. Novel suppressive function of transitional 2 B cells in experimental arthritis. J Immunol. 2007; 178:7868-78.

21. Forster R, Davalos-Misslitz AC, Rot A. CCR23 and its ligands: balancing immunity and tolerance. Nat Rev Immunol. 2008;8:362-71.

22. Frohman EM, Filippi M, Stuve O, Waxman SG, Corboy J, Phillips JT, Lucchinetti C, Wilken J, Karandikar N, Hemmer B, Monson N, De Keyser J, Hartung H, Steinman L, Oksenberg JR, Cree BA, Hauser S, Racke MK. Characterizing the mechanisms of progression in multiple sclerosis: evidence and new hypotheses for future directions. Ann Neurol. 2006;62:1345-56.

23. Greter M, Heppner FL, Lemos MP, Odermatt BM, Goebels N, Laufer T, Noelle RJ, Becher B. Dendritic cells permit immune invasion of the CNS in an animal model of multiple sclerosis. Nat Med. $2005 ; 11: 328-34$.

24. Grutzke B, Hucke S, Gross CC, Herold MVB, Posevitz-Fejfar A, Wildemann BT, Kieseier BC, Dehmel $\mathrm{T}$, Wiendl H, Klotz L, et al. Fingolimod treatment promotes regulatory phenotype and function of $\mathrm{B}$ cells. Ann Clin Transl Neurol. 2015;2(2):119-30.

25. Haas J, Hug A, Viehöver A, Fritzsching B, Falk CS, Filser A, Vetter T, Milkova L, Korporal M, Fritz B,
Storch-Hagenlocher B, Krammer PH, Suri-Payer E, Wildemann B. Reduced suppressive effect of CD4+CD25high regulatory $\mathrm{T}$ cells on the $\mathrm{T}$ cell immune response against myelin oligodendrocyte glycoprotein in patients with multiple sclerosis. Eur J Immunol. 2005;35:3343-52.

26. Haas J, Schwarz A, Korporal-Kunke M, Jarius S, Wiendl H, Kieseier BC, Wildemann B. Fingolimod does not impair T-cell release from the thymus and beneficially affects Treg function in patients with multiple sclerosis. Mult Scler J. 2015;21(12):1521-32.

27. Harp CT, Ireland S, Davis LS, Remington G, Cassidy B, Cravens PD, Stuve O, Lovett-Racke AE, Eagar TN, Greenberg BM, Racke MK, Cowell LG, Karandikar NJ, Frohman EM, Monson NL. Memory B cells from a subset of treatment-naïve relapsing-remitting multiple sclerosis patients elicit CD4 + T-cell proliferation and IFN- $\gamma$ production in response to MBP and MOG. Eur J Immunol. 2010;40:2942-56.

28. Howell OW, Reeves CA, Nicholas R, Carassiti D, Radotra B, Gentleman SM, Serafini B, Aloisi F, Roncaroli F, Magliozzi R, Reynolds R. Meningeal inflammation is widespread and linked to cortical pathology in multiple sclerosis. Brain. 2011;134:2755-71.

29. Herr DR, Chun J. Effects of LPA and S1P on the nervous system and implications for their involvement in disease. Curr Drug Targets. 2007;8(1):155-67.

30. Johnson TA, Evans BL, Durafourt BA, Blain M, Lapierre Y, Bar-Or A, Antel JP. Reduction of the peripheral blood CD56(bright) NK lymphocyte subset in FTY720-treated multiple sclerosis patients. J Immunol. 2011;187:570-9.

31. Josefowicz SZ, Lu LF, Rudensky AY. Regulatory T cells: mechanisms of differentiation and function. Annu Rev Immunol. 2012;30:531-64.

32. Kappos L, Li D, Calabresi PA, O'Connor P, Bar-Or A, Barkhof F, Yin M, Leppert D, Glanzman R, Tinbergen J, Hauser SL. Ocrelizumab in relapsing-remitting multiple sclerosis: a phase 2, randomised, placebo-controlled, multicentre trial. Lancet. 2011;378:1779-87.

33. Kappos L, Radue EW, O'Connor P, Polman C, Hohlfeld R, Calabresi P, Selmaj K, Agoropoulou C, Leyk M, Zhang-Auberson L, Burtin P, FREEDOMS Study Group. A placebo-controlled trial of oral fingolimod in relapsing multiple sclerosis. N Engl J Med. 2010;362:387-401.

34. Kasper LH, Arnold DL, Cohen JA, Coles AJ, Fox EJ, Hartung HP. Lymphocyte subset dynamics following alemtuzumab treatment in the CARE-MS II 
study. The 29th Congress of the European Committee for Treatment and Research in Multiple Sclerosis, 2013.

35. Kitz A, de Marcken M, Gautron AS, Mitrovic M, Hafler DA, DominguezVillar M. AKT isoforms modulate Th1-like Treg generation and function in human autoimmune disease. EMBO Rep. 2016;17(8):1169-83.

36. Lassmann H. Multiple sclerosis: lessons from molecular neuropathology. Exp Neurol. 2013. https://doi.org/10.1016/j.expneurol.2013.12.003.

37. Lee KM, Stott RT, Zhao G, SooHoo J, Xiong W, Lian MM, Fitzgerald L, Shi S, Akrawi E, Lei J, Deng S, Yeh $\mathrm{H}$, Markmann JF, Kim JI. TGF- $\beta$-producing regulatory $\mathrm{B}$ cells induce regulatory $\mathrm{T}$ cells and promote transplantation tolerance. Eur J Immunol. 2014;44:1728-36.

38. Lemoine S, Morva A, Youinou P, Jamin C. Regulatory B cells in autoimmune diseases: how do they work? Ann N Y Acad Sci. 2009;1173:260-7.

39. Lock C, Hermans G, Pedotti R, Brendolan A, Schadt E, Garren H, Langer-Gould A, Strober S, Cannella B, Allard J, Klonowski P, Austin A, Lad N, Kaminski N, Galli SJ, Oksenberg JR, Raine CS, Heller R, Steinman L. Gene-microarray analysis of multiple sclerosis lesions yields new targets validated in autoimmune encephalomyelitis. Nat Med. 2002;8:500-8.

40. Luessi F, Kraus S, Trinschek B, Lerch S, Ploen R, Paterka M, Roberg T, Poisa-Beiro L, Klotz L, Wiendl $\mathrm{H}$, Bopp T, Jonuleit H, Jolivel V, Zipp F, Witsch E. FTY720 (fingolimod) treatment tips the balance towards less immunogenic antigen-presenting cells in patients with multiple sclerosis. Mult Scler. 2015;21(14):1811-22.

41. Matloubian M, Lo CG, Cinamon G, Lesneski MJ, Xu Y, Brinkmann V, Allende ML, Proia RL, Cyster JG. Lymphocyte egress from thymus and peripheral lymphoid organs is dependent on S1P receptor 1 . Nature. 2004;427:355-60.

42. Matsushita T, Yanaba K, Bouaziz JD, Fujimoto M, Tedder TF. Regulatory B cells inhibit EAE initiation in mice while other B cells promote disease progression. J Clin Investig. 2008;118:3420-30.

43. Mazzola MA, Raheja R, Murugaiyan G, Rajabi $H$, Kumar D, Pertel T, Regev K, Griffin R, Aly L, Kivisakk P, Nejad P, Patel B, Gwanyalla N, Hei H, Glanz B, Chitnis T, Weiner HL, Gandhi R. Identification of a novel mechanism of action of fingolimod (FTY720) on human effector $\mathrm{T}$ cell function through TCF-1 upregulation. J Neuroinflamm. $2015 ; 12: 245$.
44. McGeachy MJ, Bak-Jensen KS, Chen Y, Tato CM, Blumenschein W, McClanahan T, Cua DJ. TGF-beta and IL- 6 drive the production of IL- 17 and IL- 10 by $\mathrm{T}$ cells and restrain $\mathrm{T}(\mathrm{H})-17$ cell-mediated pathology. Nat Immunol. 2007;8:1390-7.

45. Mehling M, Brinkmann V, Antel J, Bar-Or A, Goebels N, Vedrine C, Kristofic C, Kuhle J, Lindberg RL, Kappos L. FTY720 therapy exerts differential effects on T cell subsets in multiple sclerosis. Neurology. 2008;71:1261-7.

46. Miyazaki Y, Niino M, Fukazawa T, Takahashi E, Nonaka T, Amino I, Tashiro J, Minami N, Fujiki N, Doi S, Kikuchi S. Suppressed pro-inflammatory properties of circulating B cells in patients with multiple sclerosis treated with fingolimod, based on altered proportions of B-cell subpopulations. Clin Immunol. 2014;151(2):127-35.

47. Montes M, Zhang X, Berthelot L, Laplaud DA, Brouard S, Jin J, Rogan S, Armao D, Jewells V, Soulillou JP, Markovic-Plese S. Oligoclonal myelinreactive T-cell infiltrates derived from multiple sclerosis lesions are enriched in Th17 cells. Clin Immunol. 2009;130:133-44.

48. Pham TH, Okada T, Matloubian M, Lo CG, Cyster JG. S1P1 receptor signaling overrides retention mediated by $\mathrm{G}$ ai-coupled receptors to promote T-cell egress. Immunity. 2008;28:122-33.

49. Pestka S, Krause CD, Sarkar D, Walter MR, Shi Y, Fisher PB. Interleukin-10 and related cytokines and receptors. Annu Rev Immunol. 2004;22:929-79.

50. Ray A, Wang L, Dittel BN. IL-10-independent regulatory B-cell subsets and mechanisms of action. Int Immunol. 2015;27:531-6.

51. Roll P, Palanichamy A, Kneitz C, Dorner T, Tony HP. Regeneration of B cell subsets after transient B cell depletion using anti-CD20 antibodies in rheumatoid arthritis. Arthritis Rheum. 2006;54:2377-86.

52. Rosser EC, Mauri C. Regulatory B cells: origin, phenotype, and function. Immunity. 2015;42:607-12.

53. Serafini B, Rosicarelli B, Magliozzi R, Stigliano E, Aloisi F. Detection of ectopic B-cell follicles with germinal centers in the meninges of patients with secondary progressive multiple sclerosis. Brain Pathol. 2004;14:164-74.

54. Serpero LD, Filaci G, Parodi A, Battaglia F, Kalli F, Brogi D, Mancardi GL, Uccelli A, Fenoglio D. Fingolimod modulates peripheral effector and 
regulatory T cells in MS patients. J Neuroimmune Pharmacol. 2013;8:1106-13.

55. Sheikh NA, Jones LA. CD54 is a surrogate marker of antigen presenting cell activation. Cancer Immunol Immunother. 2008;57:1381-90.
56. Wei SH, Rosen H, Matheu MP, Sanna MG, Wang SK, Jo E, Wong CH, Parker I, Cahalan MD. Sphingosine 1-phosphate type 1 receptor agonism inhibits transendothelial migration of medullary T-cells to lymphatic sinuses. Nat Immunol. 2005;6:1228-35. 